$\underline{\text { Review Article }}$

\title{
MUCORMYCOSI (BLACK FUNGUS): A REVIEW
}

\author{
GAGANDEEP SINGH*, NARINDER SINGH, AJEET PAL SINGH, AMAR PAL SINGH
}

St. Soldier Institute of Pharmacy, Lidhran Campus, Behind NIT (R. E. C), Jalandhar-Amritsar by Pass NH-1 Jalandhar 144011, Punjab, India Email: gagandeepcandy1313@gmail.com

Received: 04 May 2021, Revised and Accepted: 02 Jul 2021

\section{ABSTRACT}

Mucormycosis is a new angioinvasive infection caused by the ubiquitous filamentous fungus of the Mucorales order of the Zygomycete class. Mucormycosis has emerged as the third most prevalent invasive mycosis in patients undergoing hematological and allogeneic stem cell transplantation, following candidiasis and aspergillosis. Sporangiospores must be inhaled on a daily basis. Members of the Mucorales are very infrequent in nasal mucus, indicating that spores in airway mucus are removed via mucociliary transport or that there is a minimal degree of airborne contamination.

Keywords: Mmucormycosis, Types, Epidemiology, Taxonomy, Treatments

(C) 2021 The Authors. Published by Innovare Academic Sciences Pvt Ltd. This is an open-access article under the CC BY license (https://creativecommons.org/licenses/by/4.0/) DOI: https://dx.doi.org/10.22159/ijcpr.2021v13i5.1888 Journal homepage: https://innovareacademics.in/journals/index.php/ijcpr

\section{INTRODUCTION}

The phylum Zygomycota is constituted of a group of lower fungi whose thalli are typically aseptate (coenocytic) and that generate zygospores after fusion of isogamic sex organs (gametangia) (gametangia). Zygomycosis (mucormycosis) is caused by moulds belonging to the order Mucorales. The order Mucorales is split into six families of relevance in human or animal disease, though most cases of human illness are caused by members of the Mucoraceae. This contains the genera Absidia, Mucor, Rhizomucor, and Rhizopus. Two more pathogenic families are the Cunninghamellaceae and the Saksenaceae. Many other organisms have been linked in human sickness, but the commonest cause of human infection is Rhizopus oryzae (arrhizus) (arrhizus) [1,2]. People get mucormycosis when they come into touch with fungus spores in the environment. Infections in the lungs or sinuses, for example, might arise after inhaling spores. These types of mucormycosis are more common in persons who have health issues or who use medications that reduce the body's capacity to fight germs and disease. Mucormycosis may also form on the skin once the fungus penetrates the skin by a cut, scrape, burn, or other sorts of skin damage $[3,4]$.

\section{Mechanism of mucormycosis}

Mucorales spores trigger an inflammatory response in healthy hosts. The most common underlying conditions for mucormycosis are associated with impaired or deficient phagocyte function. Infection is typically preceded by the skin and soft tissue infection and illicit drug use. Several features of the fungus contribute to its aggressive growth in patients. These features include the innate thermotolerance of these fungi. The capabilities of these fungi for rapid growth and cell wall remodeling also help them to withstand hostile environments. The importance of iron acquisition in the pathogenesis of mucormycosis is supported by the unique susceptibility of iron-overloaded hosts to this invasive fungal pathogen. Given the importance of iron availability in the pathogenesis of mucormycosis, interventional strategies that could reduce free iron availability to Mucorales are therapeutically appealing. Administration of newer iron chelators without xenosiderophore properties has shown protective effects in animal models. However, lack of efficacy may be specific to neutropenic patients.

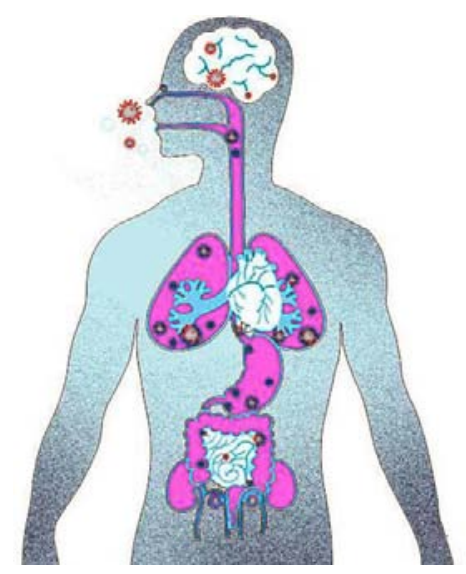

Fig. 1: Transmission of mucormycosis

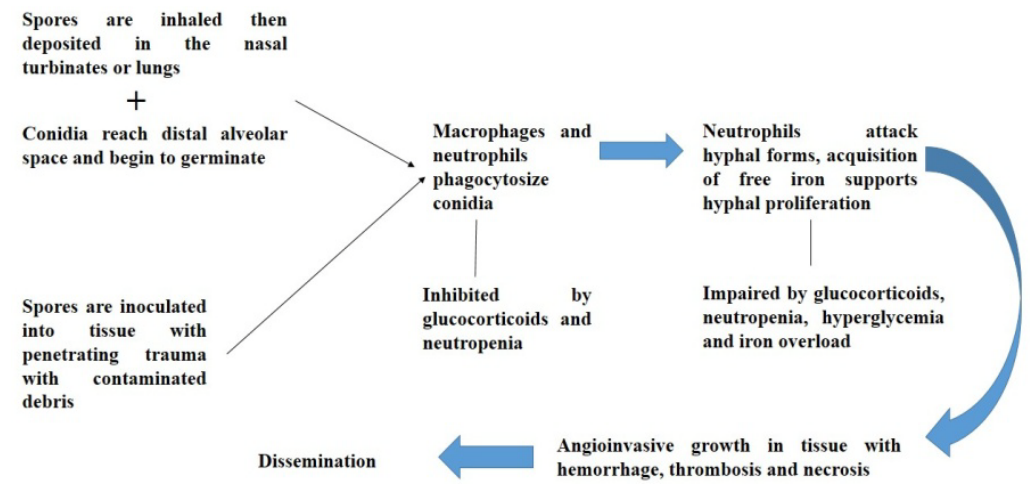

Fig. 2: Mechanism of mucormycosis 
Table 1: Types of mucormycosis [5-9]

\begin{tabular}{|c|c|c|}
\hline Types of mucormycosis & Body parts & Action \\
\hline Rhinocerebral & $\begin{array}{l}\text { sinus and } \\
\text { brain }\end{array}$ & $\begin{array}{l}\text { It is a sinus infection that may extend to the brain. This kind of mucormycosis is particularly frequent } \\
\text { in persons who have uncontrolled diabetes or who have received a kidney transplant. }\end{array}$ \\
\hline Pulmonary & Lung & $\begin{array}{l}\text { It is the most prevalent kind of mucormycosis among cancer patients and those who have received an } \\
\text { organ or stem cell transplant. }\end{array}$ \\
\hline Gastrointestinal & Stomach & $\begin{array}{l}\text { It is more prevalent in young children than in adults, particularly in preterm and low birth weight } \\
\text { babies under one month of age who have medicines, surgery, or drugs that reduce the body's capacity } \\
\text { to fight infections and illnesses. }\end{array}$ \\
\hline Cutaneous & Skin & $\begin{array}{l}\text { This happens when fungus enter the body via a skin breach (for example, after surgery, a burn, or } \\
\text { other type of skin trauma). This is the most prevalent kind of mucormycosis in persons with healthy } \\
\text { immune systems. }\end{array}$ \\
\hline Disseminated & & $\begin{array}{l}\text { This happens when an infection travels from one section of the body to another through the } \\
\text { bloodstream. The illness most usually affects the brain, although it may also damage the spleen, heart, } \\
\text { and skin. }\end{array}$ \\
\hline
\end{tabular}

\section{Taxonomy of the Zygomycota}

The Zygomycota classification is in flux, and the reader is directed to recent analyses of the phylum's phylogeny based on nuclear ribosomal sequence data [10-12]. Although 12 clades were discovered, only a few of them related to the nine Zygomycota orders that are presently recognized. Based on new molecular phylogenetic studies, we have offered a thorough phylogenetic classification of the kingdom Fungi. The most substantial changes in categorization compared to earlier study involve groupings that have historically been classified as Chytridiomycota and Zygomycota.

\section{Epidemiology}

Infections caused by moulds in the order Mucorales are referred to as mucormycosis (zygomycosis). In susceptible people, these organisms may produce rhinocerebral, pulmonary, gastrointestinal, cutaneous, or widespread infection, with the various clinical manifestations often connected with certain underlying illnesses. Despite the fact that these fungi exist in a variety of ecological niches, the limited incidence of illness caused by zygomycetes attests to their poor pathogenicity in the human host. In contrast to the fungi's alleged broad distribution, sickness in humans is restricted to persons who are seriously impaired, have diabetes mellitus, or have endured trauma. These illnesses are seen all over the globe. The respiratory system is the most prevalent route for zygomycosis agents to enter the body. Sporangiospores are likely to be deposited in nasal turbinates and inhaled into the pulmonary alveoli. Sporangiospores are inserted directly into abraded or occluded skin in the event of primary cutaneous mucormycosis. They may then reproduce and spread. Nosocomial mucormycosis outbreaks are not as prevalent as hospital-related Aspergillus infections, although they have sometimes been connected to construction or renovation activities, as well as polluted ventilation systems. Nosocomial clusters of Rhizopus rhizopodiformis and Rhizopus microsporus cutaneous infections have been linked to contaminated biomedical equipment or the use of non-sterile surgical bandages and splints [13-15].

\section{Transmission}

Spores from the environment are transmitted by inhalation, inoculation, or ingestion. Although most occurrences are infrequent, sticky bandages, wooden tongue depressors, hospital linens, negative pressure rooms, water leaks, inadequate air filtering, nonsterile medical equipment, and building architecture have all been connected to healthcare-associated epidemics.12-20 Trauma received after natural catastrophes have been linked to communityonset epidemics [16-18].

\section{Symptoms of mucormycosis}

The symptoms of mucormycosis depend on where in the body the fungus is growing. Contact your healthcare provider if you have symptoms that you think are related to mucormycosis. The symptoms of mucormycosis vary depending on where the fungus is developing in the different parts in body in table $2[3,14$, and 19$]$.

Table 2: Symptoms of mucormycosis

\begin{tabular}{|c|c|c|}
\hline Types of mucormycosis & Body parts & Symptoms \\
\hline Rhinocerebral & $\begin{array}{l}\text { Sinus and } \\
\text { brain }\end{array}$ & $\begin{array}{l}\text { - One-sided facial swelling } \bullet \text { Headache } \bullet \text { Nasal or sinus congestion } \bullet \text { Black lesions on the nasal bridge } \\
\text { or upper interior of the mouth that rapidly worsen } \bullet \text { Fever }\end{array}$ \\
\hline Pulmonary & Lung & Fever, cough, chest discomfort, and shortness of breath are all symptoms of a fever. \\
\hline Gastrointestinal & Stomach & - Abdominal pain $\bullet$ Nausea and vomiting $\bullet$ Bleeding in the intestines \\
\hline Cutaneous & Skin & $\begin{array}{l}\text { This may seem like blisters or ulcers, and the infected region may become black. } \\
\text { Other symptoms include discomfort, warmth, extreme redness, or swelling surrounding a cut. }\end{array}$ \\
\hline Disseminated & & $\begin{array}{l}\text { Because mucormycosis frequently occurs in patients who are already ill from other medical illnesses, } \\
\text { it may be difficult to determine which symptoms are attributable to mucormycosis. Patients with } \\
\text { disseminated infection in the brain may have mental status changes or go into a coma. }\end{array}$ \\
\hline
\end{tabular}

\section{Diagnosis and testing}

IF any symptoms occur of mucormycosis in your lungs or sinuses, might collect a sample of fluid from your respiratory system to send to a laboratory. A tissue biopsy, in which a tiny sample of afflicted tissue is evaluated in a laboratory for signs of mucormycosis under a microscope or in a fungal culture, may be performed by your healthcare practitioner. Depending on the location of the suspected infection, you may also need imaging tests such as a CT scan of your lungs, sinuses, or other sections of your body.

Histopathological evidence or a positive culture from a specimen from the site of infection are often required for a conclusive diagnosis of mucormycosis. Specimens from sterile bodily locations provide more indication of invasive infection than colonization. In individuals with an infection that is clinically consistent with mucormycosis, the culture of non-sterile locations (e. g., sputum) may be beneficial. Mucormycetes may be difficult to distinguish from other filamentous fungus in tissue; expert pathological and microbiological aid is often required. There are presently no regular serologic diagnostics for mucormycosis, and blood tests such as beta-D-glucan or Aspergillus galactomannan do not identify mucormycetes. Although DNA-based detection methods are promising, they are not yet completely standardized or commercially accessible [20-23].

\section{Treatment for mucormycosis}

Mucormycosis is a dangerous illness that requires antifungal medication prescribed by a doctor. 
Early detection, diagnosis, and quick delivery of suitable antifungal medication are critical for improving outcomes in mucormycosis patients. Amphotericin B lipid formulations are often utilized as firstline therapy. Most mucormycetes are resistant to amphotericin B, posaconazole, and isavuconazole. These medications are administered orally (amphotericin B, posaconazole, isavuconazole) or intravenously (amphotericin B, posaconazole, isavuconazole) (posaconazole, isavuconazole). Other medications, such as fluconazole, voriconazole, and echinocandins, are ineffective against the fungi that cause mucormycosis. Voriconazole, a medication used to treat Aspergillus, is not effective against mucormycetes, and there is some evidence that pre-exposure to voriconazole may be related with an increased incidence of mucormycosis in certain individuals [24-27].

\section{Surgery}

Surgical debridement or removal of contaminated tissue is often required, especially in cases of rhinocerebral, cutaneous, and gastrointestinal infections. When feasible, control of the underlying immunocompromising disease should be undertaken. Other therapies, such as hyperbaric oxygen therapy, have unknown effectiveness but have been beneficial in specific cases [28].

\section{Current perspective}

The patients who have suffered from such diseases, HIV/Aids, Cancer or Chemotherapy, Kidney disease, transplant, Misuse of steroids, the patients who have covid 19 positives they might be 95 percent to take Mucormycosis.

\section{Future perspective}

Advances in mucormycosis treatment may be possible only if the global medical community collaborates to establish prospective data registries, improve tools for molecular or antigen-based methods for early diagnosis and isolate fingerprinting, standardized animal models for the evaluation of new drugs, and proteomic analysis during early colonization and infection to identify potentially virulent strains.

\section{CONCLUSION}

Mucormycosis is an uncommon but rapidly spreading fungal illness that has a high fatality rate. The majority of available epidemiological research on mucormycosis are retrospective and restricted in scope. A high index of suspicion for mucormycosis based on adequate risk stratification, as well as enhanced laboratory diagnosis, are critical for improving the natural history of this lethal illness.

\section{DISCLOSURE STATEMENT}

There are no conflicts of interest.

\section{ACKNOWLEDGMENT}

It's our privilege to express profound sense of gratitude and cordial thanks to our respected chairman Mr. Anil Chopra, ViceChairperson, Ms. Sangeeta Chopra and Pro-Chairman Mr. Prince Chopra, St. Soldier Educational Society, Jalandhar for providing the necessary facilities to complete this work.

\section{FUNDING}

Nil

\section{AUTHORS CONTRIBUTIONS}

All the authors have contributed equally.

\section{CONFLICT OF INTERESTS}

\section{Declared none}

\section{REFERENCES}

1. Ribes JA, Vanover Sams CL, Baker DJ. Zygomycetes in human disease. Clin Microbiol Rev 2002;13:236-301.

2. Andrews DR, Allan A, Larbalestier RI. Tracheal mucormycosis. Ann Thorac Surg 1997;63:230-2.

3. Chamilos G, Lewis RE, Kontoyiannis DP. Lovastatin has significant activity against zygomycetes and interacts synergistically with voriconazole. Antimicrob Agents Chemother 2006;50:96-103.

4. Bauer H, Flanagan JF, Sheldon WH. The effects of metabolic alterations on experimental rhizopus orayzae (mucormycosis) infections. Yale J Biol Med 1956;29:23-32.

5. Hibbett DS, Binder M, Bischoff JF. A higher-level phylogenetic classification of the fungi. Mycol Res 2007;111:509-47.

6. Song Y, Qiao J, Giovanni G, Liu G, Yang $\mathrm{H}$, Wu J, et al. Mucormycosis in renal transplant recipients: a review of 174 reported cases external icon. BMC Infect Dis 2017;17:283.

7. Abdalla A, Adelmann D, Fahal A, Verbrugh H, Van Belkum A, De Hoog S. Environmental occurrence of Madurella mycetomatis, the major agent of human eumycetoma in sudan external icon. J Clin Microbiol 2002;40:1031-6.

8. Abramowitz I. Fatal perforations of the stomach due to mucormycosis of the gastrointestinal tract. S Afr Med J 1964;38:93-4.

9. Spellberg B, Edwards Jr J, Ibrahim A. Novel perspectives on mucormycosis: pathophysiology, presentation, and external management icon. Clin Microbiol Rev 2005;18:556-69.

10. Voigt K, Cigelnik E, O’Donnell K. Phylogeny and PCR identification of clinically important zygomycetes based on nuclear ribosomal DNA sequence data. J Clin Microbiol 1999;37:3957-64.

11. Voigt K, Wostemeyer J. Phylogeny and origin of 82 zygomycetes from all 54 genera of the mucorales and mortierellales based on combined analysis of actin and translation elongation factor EF-1alpha genes. Gene 2001;270:113-20.

12. Dannaoui E, Garcia Hermoso D. The zygomycetes. In: Kavanagh K. ed. New insights in medical mycology. Springer: New York; 2007. p. 159-83.

13. Sugar A. Agents of mucormycosis and related species. In: Mandell GL, Bennett JE, Dolin R. eds. Principles and practice of infectious diseases. $6^{\text {th }}$ edn. New York: Elsevier; 2005. p. 297384.

14. Petrikkos G, Skiada A, Lortholary O, Roilides E, Walsh TJ, Kontoyiannis DP. Epidemiology and clinical manifestations of mucormycosisexternal icon. Clin Infect Dis 2012;54:23-34.

15. James TY, Kauff F, Schoch CL. Reconstructing the early evolution of Fungi using a six-gene phylogeny. Nature 2006;443:818-22.

16. Marty FM, Cosimi LA, Baden LR. Breakthrough mucormycosis after voriconazole treatment in recipients of hematopoietic stem-cell transplants. N Engl J Med 2004;350:950-2.

17. Prabhu RM, Patel R. Mucormycosis and entomophthoramycosis: a review of the clinical manifestations, diagnosis and treatment. Clin Microbiol Infect 2004;10:31-47.

18. Andrews PA, Abbs IA, Koffman CG, Ogg CS, Williams DG. Mucormycosis in transplant recipients: possible case transmission and potentiation by cytomegalovirus. Nephrol Dial Transplant 1994;9:1194-6.

19. Talmi YP, Goldschmied Reouven A, Bakon M. Rhino-orbital and rhino-orbito-cerebral mucormycosis. Otolaryngol Head Neck Surg 2002;127:22-31.

20. Anand VK, Alemar G, Griswold JA. Intracranial complications of mucormycosis: an experimental model and clinical review. Laryngoscope 1992;102:656-62.

21. Lass Florl C. Zygomycosis: conventional laboratory diagnosis. Clin Microbiol Infect 2009;15:60-5.

22. Perlroth J, Choi B, Spellberg B. Nosocomial fungal infections: epidemiology. Diagnosis and treatment. Med Mycol 2007;45:321-46.

23. Dickinson M, Kalayanamit T, Yang CA, Pomper GJ, Franco Webb C, Rodman D. Cutaneous zygomycosis (mucormycosis) complicating endotracheal intubation: diagnosis and successful treatment. Chest 1998;114:340-2.

24. Rogers TR. Treatment of mucormycosis: current and new options. J Antimicrob Chemother 2008;61:35-9.

25. Barnett J, Behr W, Reich H. An amphotericin B-resistant case of rhinocerebral mucormycosis. Infection 1985;13:134-6.

26. Pongas GN, Lewis RE. Voriconazole-associated zygomycosis: a significant consequence of evolving antifungal prophylaxis and immunosuppression practices? External Icon Clin Microb Infec 2009;15:93-7. 
27. John BV, Chamilos G, Kontoyiannis DP. Hyperbaric oxygen as an adjunctive treatment for zygomycosisexternal icon. Clin Microbiol Infect 2005;11:515-7.
28. Bigby TD, Serota ML, Tierney LM, Matthay MA. Clinical spectrum of pulmonary Mucormycosis. Chest 1986;89:435-9. 